\title{
Article \\ Optimized Isolation of Safranal from Saffron by Solid-Phase Microextraction (SPME) and Rotatable Central Composite Design-Response Surface Methodology (RCCD-RSM)
}

\author{
Panagiota-Kyriaki Revelou ${ }^{1,2}$ (D), Spyridoula Mouzoula ${ }^{1}$, Marinos Xagoraris ${ }^{1} \mathbb{D}$, , Haralambos Evangelaras ${ }^{3}$, \\ George K. Papadopoulos ${ }^{4}$, Christos S. Pappas ${ }^{1}$ (D) and Petros A. Tarantilis ${ }^{1, *(D)}$ \\ 1 Laboratory of Chemistry, Department of Food Science and Human Nutrition, \\ Agricultural University of Athens, 75 Iera Odos, 11855 Athens, Greece; p.revelou@aua.gr (P.-K.R.); \\ mouzoulasp@gmail.com (S.M.); mxagor@aua.gr (M.X.); chrispap@aua.gr (C.S.P.) \\ 2 Department of Food Science and Technology, University of West Attica, Ag. Spyridonos Str., Egaleo, \\ 12243 Athens, Greece \\ 3 Department of Statistics and Insurance Science, University of Piraeus, 80 Karaoli \& Dimitriou St., \\ 18534 Piraeus, Greece; hevangel@unipi.gr \\ 4 Laboratory of Plant Breeding and Biometry, Department of Crop Science, Agricultural University of Athens, \\ Iera Odos 75, 11855 Athens, Greece; gpapadop@aua.gr \\ * Correspondence: ptara@aua.gr; Tel.: +30-2105294262
}

check for updates

Citation: Revelou, P.-K.; Mouzoula, S.; Xagoraris, M.; Evangelaras, H.; Papadopoulos, G.K.; Pappas, C.S.; Tarantilis, P.A. Optimized Isolation of Safranal from Saffron by Solid-Phase Microextraction (SPME) and Rotatable Central Composite DesignResponse Surface Methodology (RCCD-RSM). Separations 2022, 9, 48. https://doi.org/10.3390/separations 9020048

Academic Editors: Paraskevas D.

Tzanavaras and Petr Bednar

Received: 29 December 2021

Accepted: 7 February 2022

Published: 10 February 2022

Publisher's Note: MDPI stays neutral with regard to jurisdictional claims in published maps and institutional affiliations.

Copyright: (c) 2022 by the authors. Licensee MDPI, Basel, Switzerland. This article is an open access article distributed under the terms and conditions of the Creative Commons Attribution (CC BY) license (https:// creativecommons.org/licenses/by/ $4.0 /)$.

\begin{abstract}
Safranal is the main aroma component of saffron stigmas. It is also a great antioxidant with known pharmacological properties and is a potent indicator for the grading and authentication of saffron. In this study, the optimum extraction conditions of safranal from saffron stigmas were investigated using solid-phase microextraction-gas chromatography-mass spectrometry (SPME-GCMS) and response surface methodology (RSM). A rotatable-central composite design was applied, and a linear regression model has been used for the model building. The optimized factors were as follows: sample weight $(15 \mathrm{mg})$, water volume $(4 \mathrm{~mL})$, exposure time in the headspace $(20 \mathrm{~min})$, and extraction temperature $\left(45^{\circ} \mathrm{C}\right)$. All factors were found significant; however, extraction temperature and exposure time were the most important for the isolation of safranal. The obtained model was successfully validated with a test set of saffron samples analyzed under the optimum extraction conditions. The optimized SPME extraction conditions of safranal found in this study contribute to the efforts towards the detection of saffron authentication and adulteration.
\end{abstract}

Keywords: Crocus sativus; safranal; gas chromatography-mass spectrometry; solid-phase microextraction; optimization; response surface methodology; saffron

\section{Introduction}

Saffron, the dried red stigmas of Crocus sativus L., is highly valued in the food industry for its aroma, taste, and color and is one of the world's most expensive spices. Approximately 150,000 flowers are required to produce a single kilogram of saffron, which is subsequently sold for \$1400-2600 USD (price for export) and \$2-12 USD per gram (retail price) [1-3]. It has been estimated that the global annual production of saffron is approximate 205 tons, 80 percent of which comes from Iran, while Spain and Greece export around 60 and 4.5 tons, respectively [4].

Saffron releases its aroma after it has undergone a thermal process, with safranal being the main component [5-7]. Although various other components-and not only safranal-play a role in producing the saffron aroma, safranal is viewed as the key sensorial compound, and this suggests that the development of methods for the extraction and analysis of safranal would be extremely useful for categorizing and grading saffron's commercial quality $[6,8,9]$. Safranal is a highly rated antioxidant and acts as a protective 
agent against indomethacin-induced gastric ulcers, while in vitro tests have shown that it is also effective against certain cancer cells [10].

In order to differentiate between different qualities of saffron, the sector uses a spectrophotometric method described at ISO Normative 3632-1:2011 [11] to categorize saffron according to the strength of its aroma (expressed as safranal), flavor (expressed as picrocrocin), and coloring (expressed as crocin). Nevertheless, this type of general analysis cannot tackle the issue of quality grading, which would make a positive contribution to the international market in saffron sales $[8,12-15]$. One further disadvantage to using this method is its inability to ensure the authenticity of saffron [16-18]. The safranal index used by ISO Normative cannot be harnessed to make distinctions between commercial samples, since safranal is not fully solubilized in water-the solvent used in the method for UV determination at $\lambda=330 \mathrm{~nm}[14,15]$. It has also been pointed out that the cis-crocetin ester isomers interfere at precisely the same wavelength $[19,20]$.

One commonly used method for determining food aroma compounds is the combination of solid-phase microextraction (SPME) and gas chromatography-mass spectrometry (GC-MS). This approach has a number of advantages, namely the following: it precludes the co-extraction of less volatile compounds from real sample matrices and does away with the need to use toxic solvents and laborious sample preparations [21]. This method has been employed to quantify safranal in a range of saffron samples [22-26], saffron drink [9], for the detection of adulterants [18], and for the purpose of geographical discrimination of saffron $[27,28]$. However, several factors that affect the SPME extraction of safranal such as the quantity of saffron and the volume of water added have not been yet evaluated and optimized. In particular, the quantity of saffron can be a very important factor, as it increases the cost of analysis.

This study set out to examine the factors that affect the extraction of safranal by SPME and methods of upgrading and improving the SPME procedure through the optimization of the factors affecting the analysis in order to attain the highest possible concentration of safranal. GC-MS was used to analyze the aroma profile, and experimental design was based on a five-level rotatable central composite design (RCCD), combined with the application of response surface methodology (RSM).

\section{Materials and Methods}

\subsection{Saffron Samples}

Saffron and dried red stigmas (11 samples) were originated from the Kozani prefecture and were offered by the "Cooperative of Saffron producers, Kozani Greece". The stigmas of Crocus sativus L. were dried from the producers by the traditional drying method. Stigmas were spread on a silk sieve and dried at a controlled temperature of 25 to $30^{\circ} \mathrm{C}$ for 12 to $24 \mathrm{~h}$. The moisture of the final product varied between 10 and $12 \%$. Samples were collected from 2018 to 2020.

\subsection{Experimental Design}

Experimental design was performed using the Design-Expert 11.0.5.0 software (StatEase, Inc., Minneapolis, MN, USA). A five-level rotatable central composite design (CCD) in combination with RSM methodology $[29,30]$ with four quantitative factors (A, B, C, and D) and one response (safranal) were used. A total of 30 runs were analyzed by a linear design domain (Table 1) using a randomly selected saffron sample. Analysis of variance (ANOVA) and the coefficient of determination $\left(R^{2}\right)$ were used to test the model's fit. The robustness of the model was confirmed by the response data of 10 different samples of saffron, which were provided from various producers of the Kozani prefecture collected in years 2018 (1 sample), 2019 ( 8 samples), and 2020 (1 sample). The samples were analyzed under the optimized SPME conditions proposed by the model. 
Table 1. Central composite design for the four independent experimental factors (A, B, C, and D) along with the experimental values of the response (safranal).

\begin{tabular}{|c|c|c|c|c|c|}
\hline Run & $\begin{array}{l}\text { A: Sample Weight } \\
\text { (mg) }\end{array}$ & $\begin{array}{c}\text { B: Water Volume } \\
(\mathrm{mL})\end{array}$ & $\begin{array}{c}\text { C: Temperature } \\
\left({ }^{\circ} \mathrm{C}\right)\end{array}$ & $\begin{array}{c}\text { D: Exposure Time } \\
\text { (min) }\end{array}$ & $\begin{array}{l}\text { Safranal } \\
\text { (\% Area) }\end{array}$ \\
\hline 1 & 15 & 4 & 45 & 40 & 95.3 \\
\hline 2 & 35 & 4 & 45 & 20 & 95.5 \\
\hline 3 & 35 & 2 & 45 & 40 & 93.4 \\
\hline 4 & 15 & 4 & 55 & 40 & 94.6 \\
\hline 5 & 15 & 2 & 55 & 20 & 94.6 \\
\hline 6 & 25 & 3 & 50 & 30 & 94.9 \\
\hline 7 & 35 & 4 & 55 & 20 & 94.7 \\
\hline 8 & 25 & 3 & 40 & 30 & 95.4 \\
\hline 9 & 15 & 4 & 45 & 20 & 96.2 \\
\hline 10 & 35 & 4 & 45 & 40 & 94.8 \\
\hline 11 & 15 & 2 & 45 & 40 & 95.4 \\
\hline 12 & 25 & 5 & 50 & 30 & 94.9 \\
\hline 13 & 25 & 3 & 50 & 30 & 95.1 \\
\hline 14 & 25 & 3 & 60 & 30 & 92.0 \\
\hline 15 & 25 & 3 & 50 & 50 & 93.6 \\
\hline 16 & 15 & 2 & 45 & 20 & 94.9 \\
\hline 17 & 35 & 2 & 45 & 20 & 94.7 \\
\hline 18 & 25 & 3 & 50 & 30 & 94.7 \\
\hline 19 & 45 & 3 & 50 & 30 & 93.9 \\
\hline 20 & 5 & 3 & 50 & 30 & 94.4 \\
\hline 21 & 15 & 4 & 55 & 20 & 94.9 \\
\hline 22 & 35 & 2 & 55 & 20 & 94.4 \\
\hline 23 & 25 & 3 & 50 & 10 & 95.4 \\
\hline 24 & 35 & 2 & 55 & 40 & 93.2 \\
\hline 25 & 15 & 2 & 55 & 40 & 92.9 \\
\hline 26 & 35 & 4 & 55 & 40 & 93.1 \\
\hline 27 & 25 & 1 & 50 & 30 & 93.1 \\
\hline 28 & 25 & 3 & 50 & 30 & 94.3 \\
\hline 29 & 25 & 3 & 50 & 30 & 93.9 \\
\hline 30 & 25 & 3 & 50 & 30 & 94.6 \\
\hline
\end{tabular}

\subsection{Isolation and Analysis of Volatile Compounds}

Saffron dried stigmas were ground and transferred in a $15 \mathrm{~mL}$ screw top $(22.7 \times 86 \mathrm{~mm})$ vial with PTFE/silicone septa, adding the corresponding volume of distilled water ( $\mathrm{pH} 7.0)$. Then, a portion of $7 \mu \mathrm{L}$ of cyclohexanone (Alfa Aesar, Kandal, Germany) was added as an internal standard for the semi-quantification of volatile compounds. Safranal was semiquantified by dividing the peak area of the compounds by the peak area of the internal standard, multiplying this ratio by the initial concentration of the internal standard. The samples were equilibrated for $30 \mathrm{~min}$ in a water bath $\left( \pm 1^{\circ} \mathrm{C}\right.$ accuracy). Isolation of the volatile fraction of saffron was performed based on the RCCD runs reported at Table 1 and the SPME solution proposed by the model.

For SPME experiments, a divinylbenzene/carboxen/polydimethylsiloxane (DVB/CAR/ PDMS) 50/30 $\mu \mathrm{m}$ fiber of $1 \mathrm{~cm}$ length (Supelco, Bellefonte, PA, USA) was used. Conditioning of fiber was performed at $270{ }^{\circ} \mathrm{C}$. GC-MS analysis was achieved using a Trace Ultra Gas Chromatograph (Thermo Scientific Inc., Waltham, MA, USA), coupled to a Mass Spectrometer (DSQII, Thermo Scientific Inc., Waltham, MA, USA). A Restek Rtx-5MS (30 $\mathrm{m} \times 0.25 \mathrm{~mm}$ i.d., $0.25 \mu \mathrm{m}$ film thickness) column was used. Helium was the carrier gas with a flow rate of $1 \mathrm{~mL} \cdot \mathrm{min}^{-1}$. Desorption was performed at an inlet temperature of $260^{\circ} \mathrm{C}$ for $3 \mathrm{~min}$, operated in the splitless mode, using a $0.8 \mathrm{~mm}$ injector liner (SGE International Pty Ltd., Ringwood, Australia). Chromatographic analysis was performed with the following conditions: initial temperature $40^{\circ} \mathrm{C}$, held for $6 \mathrm{~min}$, heated to $120^{\circ} \mathrm{C}$ at a rate of $5{ }^{\circ} \mathrm{C} / \mathrm{min}$, heated to $160{ }^{\circ} \mathrm{C}$ at a rate of $3{ }^{\circ} \mathrm{C} \mathrm{min}$, heated to $250{ }^{\circ} \mathrm{C}$ at a rate $15^{\circ} \mathrm{C} / \mathrm{min}$, and held to $250^{\circ} \mathrm{C}$ for $1 \mathrm{~min}$. The MS source and quadrupole temperatures were $240{ }^{\circ} \mathrm{C}$ and $150{ }^{\circ} \mathrm{C}$, respectively. The transfer line temperature was $290^{\circ} \mathrm{C}$. The acquisition mode was electron impact $70 \mathrm{eV}$ with a mass range of $m / z$ 35-650. GC-EI-MS data have been recorded in full scan mode. Peak identification was performed by utilizing the Wiley 275 mass spectra library, and the arithmetic index provided by Adams [31]. Retention Index 
(RI) values were calculated based on the observed retention times of n-alkanes $\left(\mathrm{C}_{8}-\mathrm{C}_{20}\right)$ standard (Supelco, Bellefonte, PA, USA).

\section{Results and Discussion}

\subsection{Evaluation of Saffron Volatile Compounds}

Chromatograms at extraction temperatures 45,50 and $60^{\circ} \mathrm{C}$ are presented at Figure 1. The percentage area of safranal depending on the SPME extraction conditions was very high and ranged from 92.0 to $96.2 \%$ (Table 1 ), while the content of safranal was $17.4 \pm 25.6 \mathrm{mg} \cdot \mathrm{g}^{-1}$. Literature reports suggest that the extraction method and the geographical origin of saffron may have a high impact on safranal content. Urbani et al. [26] reported an average content of safranal at $69.3 \%$ of the total volatile fraction in Italian saffron samples from Cascia, extracted by SPME. D'Auria et al. [22] used the same technique and reported a safranal percentage between 41.13 and $83.97 \%$ in Italian samples from Salerno and Sardinia. The significant differences in safranal content observed among these literature reports and the current study can be attributed to the different geographical origin of the samples as well as in the differences of the conditions applied for the SPME extraction.

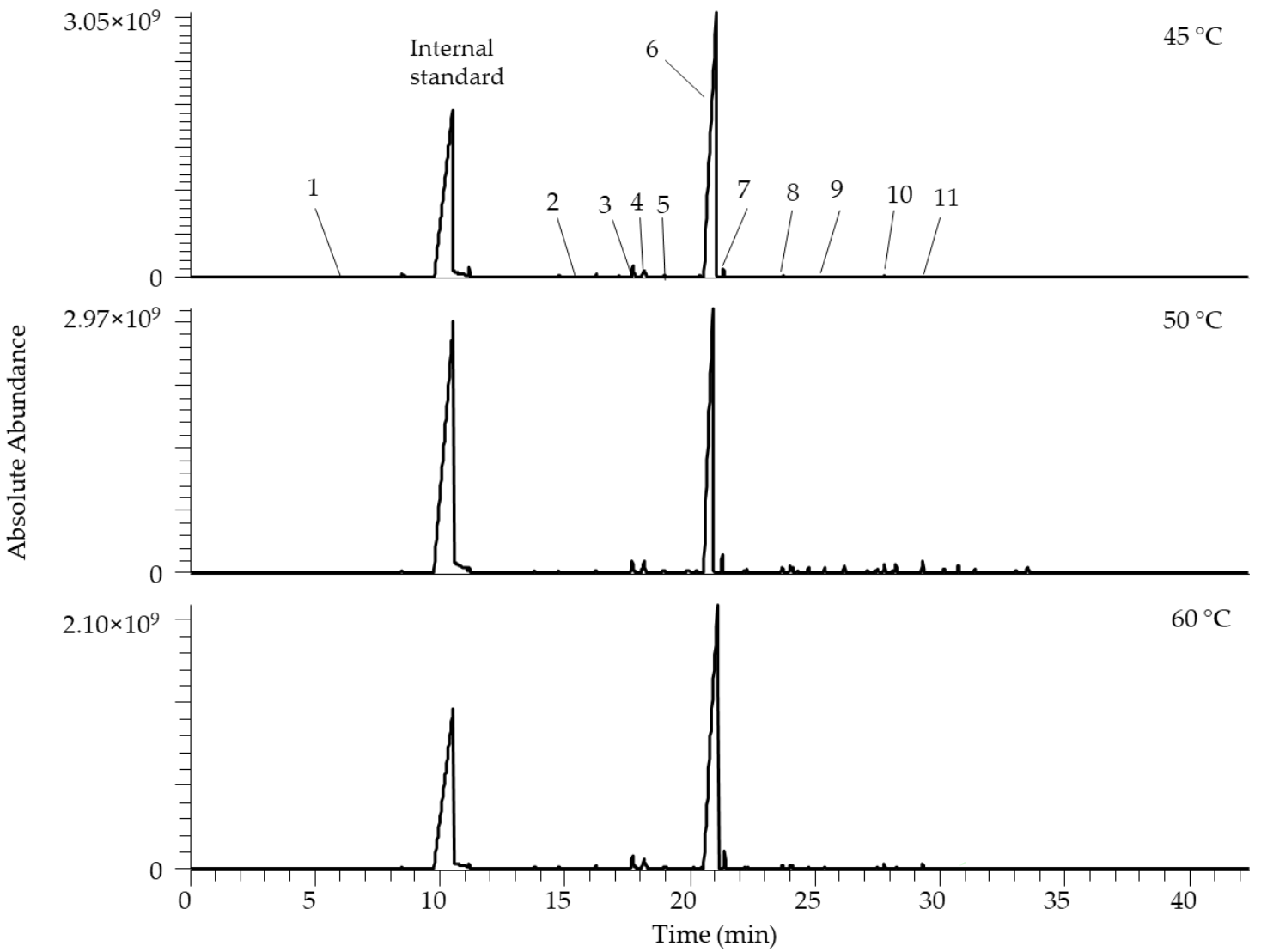

Figure 1. Chromatograms at extraction temperatures 45,50 and $60{ }^{\circ} \mathrm{C}$. (1) hexanal; (2) 3,5,5trimethylcyclohex-3-en-1-one; (3) 2,6,6-trimethylcyclohexa-1,4-diene-1-carbaldehyde; (4) 3,5,5trimethylcyclohex-2-en-1-one (isophorone); (5) 2,6,6-trimethylcyclohex-2-ene-1,4-dione (4-ketoisophorone); (6) 2,6,6-trimethylcyclohexa-1,3-diene-1-carbaldehyde (safranal); (7) 3,5,5-trimethyl-4-methylenecyclohex2-en-1-one; (8) 7,7-dimethylbicyclo[4.1.0]hept-3-ene-2,5-dione; (9) megastigma-4,6(E),8(E)-triene; (10) 4-(2,6,6-trimethylcyclohex-1-en-1-yl)butan-2-one; (11) (E)-4-(2,6,6-trimethylcyclohexen-1-yl)but-3en-2-one ( $\beta$-ionone).

Kanakis et al. [32] applied a micro simultaneous hydro distillation-extraction method in stigmas of Crocus sativus L. of Greek origin dried by the traditional method and reported a relative percentage of safranal between 50.0 and $70.8 \%$, while after ultrasound-assisted 
extraction, the content of safranal ranged between 8.7 and $41.2 \%$. Safranal content in Iranian saffron samples after ultrasound assisted extraction was found at 26.29\% [8].

Safranal, isophorone, and 4-ketoisophorone are the most common constituents of saffron aroma regardless the extraction method and geographical origin $[5,8,26,28,32-34]$. 2,6,6-trimethylcyclohexa-1,4-diene-1-carbaldehyde, isophorone, and 4-ketoisophorone have been previously detected in saffron samples from Greece, Iran, Italy, and Spain by ultrasound extraction with diethyl ether [34].

The above compounds along with 3,5,5-trimethylcyclohex-3-en-1-one, 7,7-dimethylbicyclo [4.1.0]hept-3-ene-2,5-dione, 4-(2,6,6-trimethylcyclohex-1-en-1-yl)butan-2-one and $\beta$-ionone have been isolated by SPME-GC-MS with a DVB/CAR/PDMS fiber in Italian saffron samples [28]. Hexanal has been detected by the same technique in Greek and Spanish saffron samples, while megastigma-4,6(E),8(E)-triene has been detected in Greek, Iranian, and Spanish saffron samples [27].

\subsection{Model Fitting}

An RCCD was chosen in the current study as it permits the analysis of experimental factors at five levels offering reduced prediction error. The combination of RCCD with RSM provides useful information about the interactions among the experimental factors without the need to perform unnecessary experiments and simultaneously obtaining optimized results for the response. Four experimental factors were investigated in this study in order to determine the most suitable conditions for the extraction of safranal from the saffron stigmas by SPME. RCCD experiments were run in a random order for reducing the effect of uncontrolled variables. The RCCD design used in this study includes 16 factorial points, 6 center points, and 8 axial points selecting the value of $\alpha=2$ for establishing rotatability conditions.

The data acquired by the RCCD were generated into a response function linear model expressed by the following coded Equation (1):

$$
\mathrm{Y}=94.44-0.2558 \mathrm{~A}+0.3750 \mathrm{~B}-0.6181 \mathrm{C}-0.4528 \mathrm{D}
$$

where $\mathrm{Y}$ is the percentage area of safranal, while A, B, C, and D are the coded values of sample weight, water volume, temperature, and exposure time, respectively.

Residual analysis does not show any discrepancies from the linear model assumptions (Figure 2a), while the lambda value 1.00, obtained from the Box-Cox test (Figure 2b) suggested that the data did not require a specific transformation.

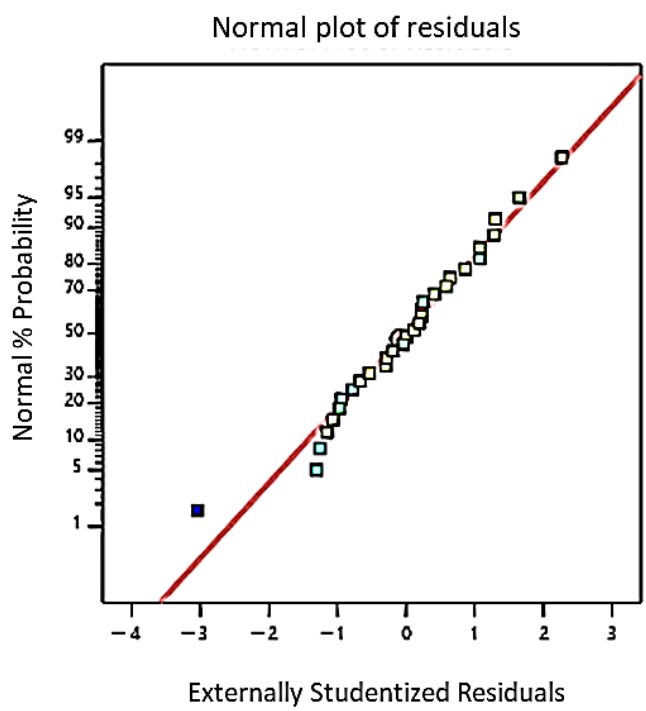

(a)

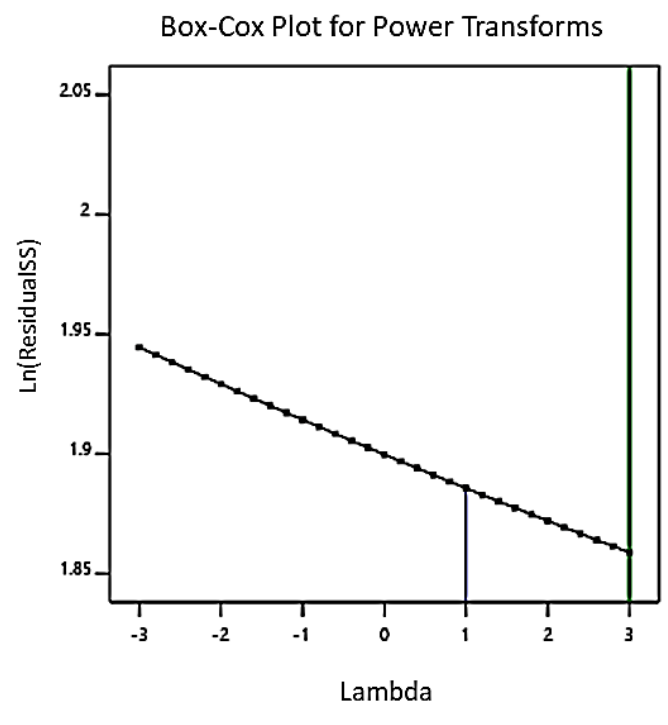

(b)

Figure 2. (a) Normal plot of residuals; (b) Box-Cox plot. 
Analysis of variance (ANOVA) was used to confirm the adequacy of the linear model (Table 2). The model is significant with a $p$-value $<0.0001$. All model terms were significant ( $p$-value $<0.05)$. The extraction temperature seems to have a significant effect as shown from the differences observed in the absolute abundance between the chromatograms obtained at 45,50 and $60{ }^{\circ} \mathrm{C}$ (Figure 1). The non-significance of the lack of fit ( $p$-value $>0.05$ ) showed that the linear model was valid for the current study. Moreover, the values of $\mathrm{R}^{2}$ and adjusted $R^{2}$ were 0.7428 and 0.7017 , which are in reasonable agreement with the predicted $\mathrm{R}^{2}$ value of 0.6173 , thus indicating a high correlation among the predicted and actual values.

Table 2. Analysis of variance results for the experimental design.

\begin{tabular}{cccccc}
\hline Source & Sum of Squares & DF $^{\mathbf{1}}$ & Mean Square & F-Value & $p$-Value \\
\hline Model & 19.04 & 4 & 4.76 & 18.05 & $<0.0001^{2}$ \\
A-Sample weight & 1.57 & 1 & 1.57 & 5.96 & 0.0221 \\
B-Water volume & 3.37 & 1 & 3.37 & 12.80 & 0.0015 \\
C-Extraction temperature & 9.17 & 1 & 9.17 & 34.78 & $<0.0001$ \\
D-Exposure time & 4.92 & 1 & 4.92 & 18.67 & 0.0002 \\
Residual & 6.59 & 25 & 0.26 & & \\
Lack of fit & 5.76 & 20 & 0.29 & 1.75 & $0.2801^{3}$ \\
Pure error & 0.83 & 5 & 0.17 & & \\
Cor. total & 25.63 & 29 & & & \\
\hline
\end{tabular}

${ }^{1}$ DF: degree of freedom; ${ }^{2}$ significant; ${ }^{3}$ not significant.

\subsection{Response Analysis and Optimization}

Figure 3 shows the contour plots of the estimated response surface. These plots are helpful for selecting the levels of the factors that optimize the response of interest. For example, from Figure 3a, it is evident that safranal increases when water volume increases close to $4 \mathrm{~mL}$ and sample weight decreases to $15 \mathrm{mg}$.

Figure $3 \mathrm{~b}$ indicates that the optimum extraction temperature is around $45^{\circ} \mathrm{C}$ and a further temperature increase has negative impacts on the response. Similarly, an increase on exposure time above $20 \mathrm{~min}$ results in a gradual decrease in safranal (Figure 3c). The influence of extraction temperature and exposure time in the volatile fraction of solid samples of saffron has been investigated by D'Archivio et al. [28] and Di Donato et al. [18] by using a three-level factorial design of experiments. In both studies, the optimum exposure time was found at $30 \mathrm{~min}$, while the optimum extraction temperature was at $45^{\circ} \mathrm{C}$ [28] and $50{ }^{\circ} \mathrm{C}$ [18]. Although, in the current study, the amount of saffron sample and the addition of water proved to be significant and had a high contribution on the obtained amount of safranal, a lack of literature reports still exists regarding the evaluation of these factors in the saffron aroma. Previous research studies utilized higher amounts of saffron for the SPME-GC-MS analysis of aroma, increasing the cost of the analysis. D'Archivio et al. [28] used 20-40 mg of saffron for the SPME experiments, while other studies used $50 \mathrm{mg}$ [27] and $100 \mathrm{mg}[22,23,35,36]$. In the present study, the RSM model suggested that only $15 \mathrm{mg}$ of saffron was required for SPME-GC-MS analysis.

The desirability function was used in order to find the optimum isolation conditions of safranal. The four factors were set to the option "in range," while safranal was set to the "maximize" option. The upper limit for safranal was set at $97.0 \%$ area. Then, the software provided 100 optimization solutions; however, based on the highest desirability value obtained (0.828), the software suggested that the optimum conditions for the extraction of safranal were A: $15 \mathrm{mg}$; B: $4 \mathrm{~mL} ; \mathrm{C}: 45^{\circ} \mathrm{C}$; and D: $20 \mathrm{~min}$ (Figure 4). The predicted mean (\% area) was estimated from the model at $96.1 \pm 0.5 \%$. A test set comprising 10 samples was analyzed under the optimized extraction conditions. The obtained results were within the prediction interval, providing an experimental average of $95.6 \%$. 


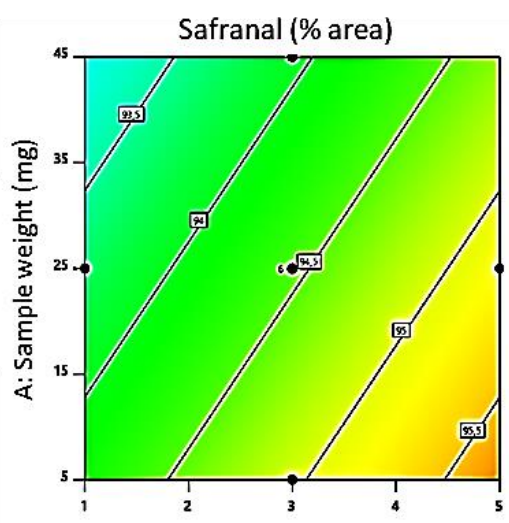

B: Water volume $(\mathrm{mL})$

(a)

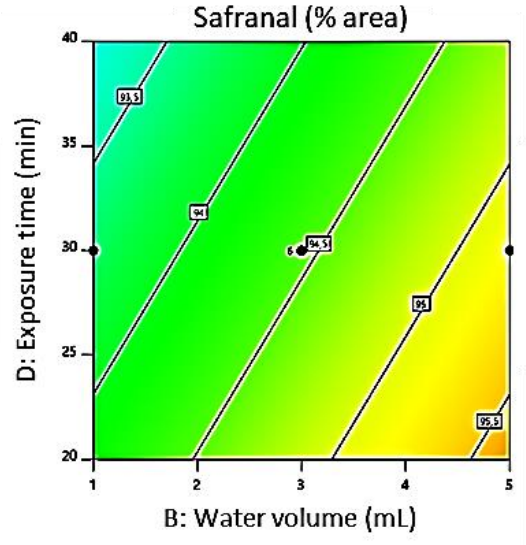

(d)

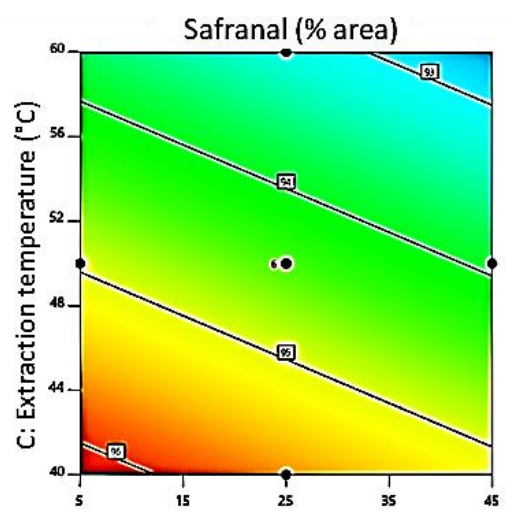

A: Sample weight (mg)

(b)

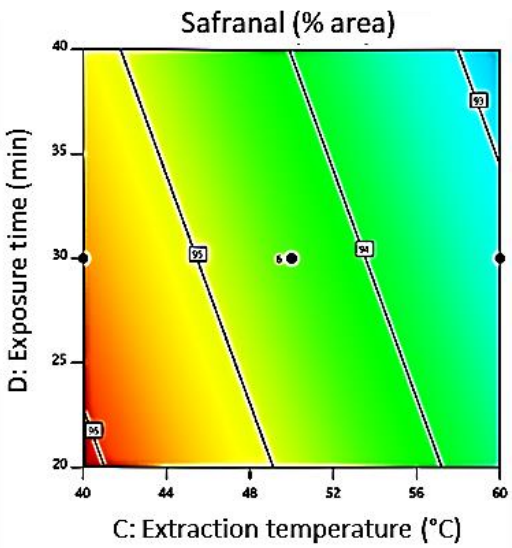

(e)

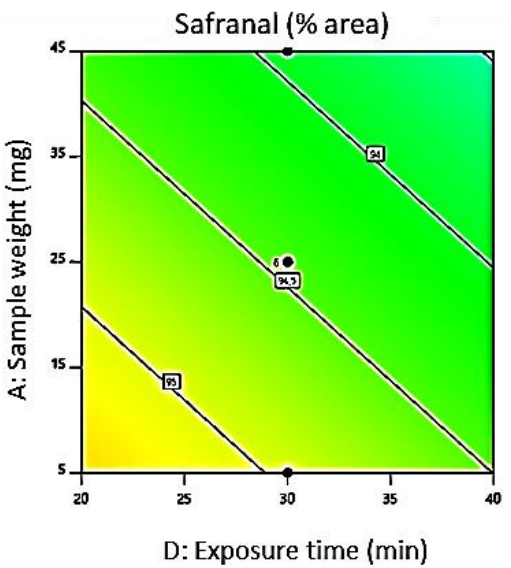

(c)

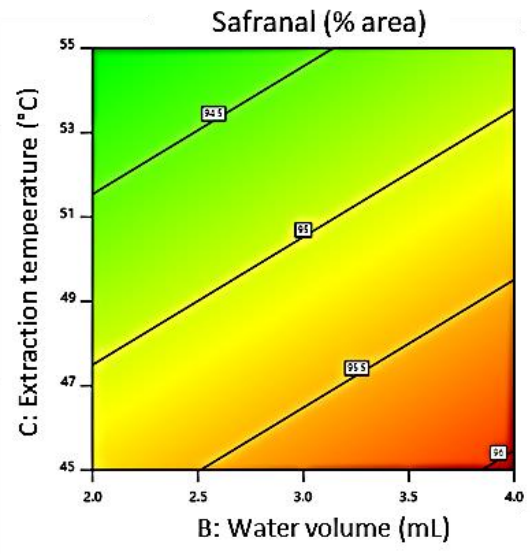

(f)

Figure 3. Contour plots of the interaction between; (a) sample weight and water volume; (b) sample weight and temperature; (c) sample weight and exposure time; (d) exposure time and water volume; (e) exposure time and extraction temperature; (f) extraction temperature and water volume.
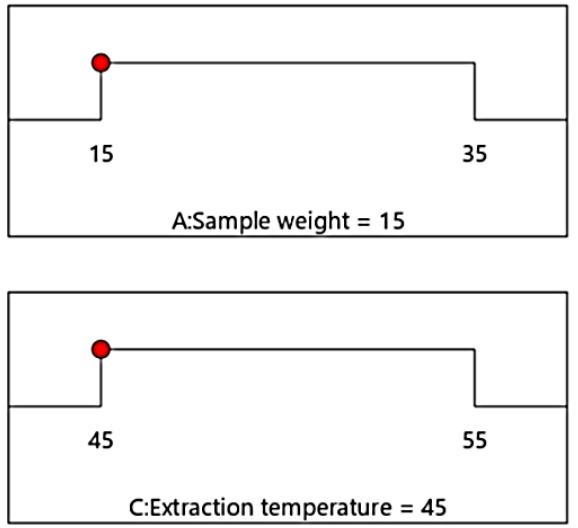
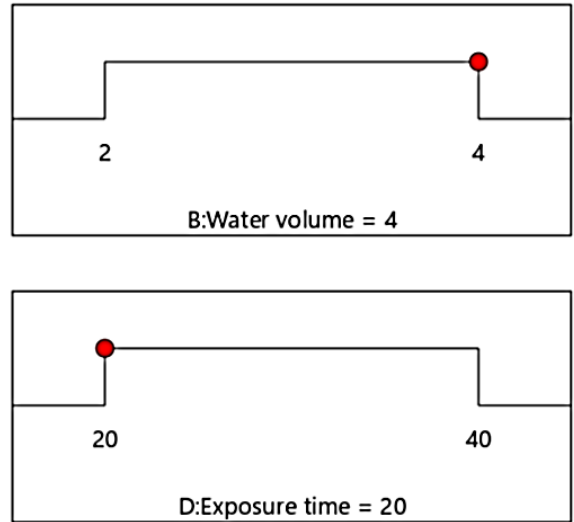

D:Exposure time $=20$

Figure 4. Optimized conditions for the isolation of safranal by SPME proposed by the model using the desirability function.

\section{Conclusions}

In this study, the factors affecting the isolation of safranal from saffron by SPME were investigated. A five-level rotatable-central composite design was chosen and used in combination with response surface methodology. The factors evaluated included the 
saffron sample weight, the volume of water added, the exposure time of SPME fiber in the sample headspace, and the extraction temperature. All factors were found to be significant ( $p$-value < 0.05); however, the extraction temperature and exposure time were the most important. A validation set of 10 samples was used to confirm model efficiency. The average of percentage area of safranal obtained from the validation set was $95.6 \%$, which was within the prediction interval of the model $(96.1 \pm 0.5 \%)$. By taking into consideration the high contribution of safranal on the aroma profile and the potential of this compound as an index of commercial quality of saffron, the data obtained from the current study are important for the characterization, authentication, and adulteration of saffron.

Author Contributions: Conceptualization, P.A.T. and P.-K.R.; methodology, P.-K.R., P.A.T., G.K.P. and H.E.; software, P.-K.R. and M.X.; validation, P.-K.R. and S.M.; formal analysis, S.M. and P.-K.R.; investigation, P.-K.R. and S.M.; resources, P.-K.R. and M.X.; data curation, S.M. and P.-K.R.; writingoriginal draft preparation, P.-K.R.; writing—review and editing, P.-K.R., S.M., M.X., H.E., G.K.P., C.S.P. and P.A.T.; visualization P.-K.R.; supervision, C.S.P. and P.A.T.; project administration, P.A.T. All authors have read and agreed to the published version of the manuscript.

Funding: This research received no external funding.

Institutional Review Board Statement: Not applicable.

Informed Consent Statement: Not applicable.

Data Availability Statement: Not available.

Conflicts of Interest: The authors declare no conflict of interest.

\section{References}

1. Winterhalter, P.; Straubinger, M. SAFFRON-Renewed interest in an ancient spice. Food Rev. Int. 2000, 16, 39-59. [CrossRef]

2. Saffron Prices. Available online: https:/ / saffronprices.com/saffron-prices-2/ (accessed on 19 January 2022).

3. Saffron Prices (Update 2022). Available online: https:/ / kohanrishe.net/saffron-price/ (accessed on 19 January 2022).

4. Saravanan, K.; Egbuna, C.; Averal, H.I.; Kannan, S.; Elavarasi, S.; Bahadur, B. (Eds.) Drug Development for Cancer and Diabetes: A Path to 2030, 1st ed.; Apple Academic Press: Palm Bay, FL, USA, 2020.

5. Tarantilis, P.A.; Polissiou, M.G. Isolation and Identification of the Aroma Components from Saffron (Crocus sativus). J. Agric. Food Chem. 1997, 45, 459-462. [CrossRef]

6. Carmona, M.; Zalacain, A.; Salinas, M.R.; Alonso, G.L. A New Approach to Saffron Aroma. Crit. Rev. Food Sci. Nutr. 2007, 47, 145-159. [CrossRef] [PubMed]

7. Sharafzadeh, S. Saffron: A Concise Review of Researches. Adv. Environ. Biol. 2011, 5, 1617-1621.

8. Jalali-Heravi, M.; Parastar, H.; Ebrahimi-Najafabadi, H. Characterization of Volatile Components of Iranian Saffron Using Factorial-Based Response Surface Modeling of Ultrasonic Extraction Combined with Gas Chromatography-Mass Spectrometry Analysis. J. Chromatogr. A 2009, 1216, 6088-6097. [CrossRef] [PubMed]

9. Feyzi, S.; Varidi, M.; Housaindokht, M.R.; Es'haghi, Z. Innovative Method for Analysis of Safranal under Static and Dynamic Conditions through Combination of HS-SPME-GC Technique with Mathematical Modelling. Phytochem. Anal. 2020, 31, 564-574. [CrossRef]

10. Rezaee, R.; Hosseinzadeh, H. Safranal: From an Aromatic Natural Product to a Rewarding Pharmacological Agent. Iran J. Basic Med. Sci. 2013, 16, 12-26. [PubMed]

11. ISO. ISO 3632-1:2011. Available online: https://www.iso.org/cms/render/live/en/sites/isoorg/contents/data/standard/04/4 5/44523.html (accessed on 27 December 2021).

12. Anastasaki, E.; Kanakis, C.; Pappas, C.; Maggi, L.; del Campo, C.P.; Carmona, M.; Alonso, G.L.; Polissiou, M.G. Differentiation of Saffron from Four Countries by Mid-Infrared Spectroscopy and Multivariate Analysis. Eur. Food Res. Technol. 2010, 230, $571-577$. [CrossRef]

13. Culleré, L.; San-Juan, F.; Cacho, J. Characterisation of Aroma Active Compounds of Spanish Saffron by Gas ChromatographyOlfactometry: Quantitative Evaluation of the Most Relevant Aromatic Compounds. Food Chem. 2011, 127, 1866-1871. [CrossRef]

14. Lech, K.; Witowska-Jarosz, J.; Jarosz, M. Saffron Yellow: Characterization of Carotenoids by High Performance Liquid Chromatography with Electrospray Mass Spectrometric Detection. J. Mass Spectrom. 2009, 44, 1661-1667. [CrossRef]

15. Maggi, L.; Sánchez, A.M.; Carmona, M.; Kanakis, C.D.; Anastasaki, E.; Tarantilis, P.A.; Polissiou, M.G.; Alonso, G.L. Rapid Determination of Safranal in the Quality Control of Saffron Spice (Crocus sativus L.). Food Chem. 2011, 127, 369-373. [CrossRef]

16. Lozano, P.; Castellar, M.R.; Simancas, M.J.; Iborra, J.L. A Quantitative High-Performance Liquid Chromatographic Method to Analyse Commercial Saffron (Crocus sativus L.) Products. J. Chromatogr. A 1999, 830, 477-483. [CrossRef] 
17. Zougagh, M.; Ríos, A.; Valcárcel, M. An Automated Screening Method for the Fast, Simple Discrimination between Natural and Artificial Colorants in Commercial Saffron Products. Anal. Chim. Acta 2005, 535, 133-138. [CrossRef]

18. Di Donato, F.; D'Archivio, A.A.; Maggi, M.A.; Rossi, L. Detection of Plant-Derived Adulterants in Saffron (Crocus sativus L.) by HS-SPME/GC-MS Profiling of Volatiles and Chemometrics. Food Anal. Methods 2021, 14, 784-796. [CrossRef]

19. Hadizadeh, F.; Mahdavi, M.; Emami, S.A.; Khashyarmanesha, Z.; Hassanzadeh, M.; Asili, J.; Seifi, M.; Nassirli, H.; Shariatimoghadam, A.; Noorbakhsh, R. Evaluation of ISO Method in Saffron Qualification. Acta Hortic. 2007, 739, 410. [CrossRef]

20. Tarantilis, P.A.; Polissiou, M.; Manfait, M. Separation of Picrocrocin, Cis-Trans-Crocins and Safranal of Saffron Using HighPerformance Liquid Chromatography with Photodiode-Array Detection. J. Chromatogr. A 1994, 664, 55-61. [CrossRef]

21. Merkle, S.; Kleeberg, K.K.; Fritsche, J. Recent Developments and Applications of Solid Phase Microextraction (SPME) in Food and Environmental Analysis-A Review. Chromatography 2015, 2, 293-381. [CrossRef]

22. D'Auria, M.; Mauriello, G.; Rana, G.L. Volatile Organic Compounds from Saffron. Flavour Fragr. J. 2004, 19, 17-23. [CrossRef]

23. Du, H.; Wang, J.; Hu, Z.; Yao, X. Quantitative Structure-Retention Relationship Study of the Constituents of Saffron Aroma in SPME-GC-MS Based on the Projection Pursuit Regression Method. Talanta 2008, 77, 360-365. [CrossRef]

24. Bononi, M.; Milella, P.; Tateo, F. Gas Chromatography of Safranal as Preferable Method for the Commercial Grading of Saffron (Crocus sativus L.). Food Chem. 2015, 176, 17-21. [CrossRef]

25. Condurso, C.; Cincotta, F.; Tripodi, G.; Verzera, A. Bioactive Volatiles in Sicilian (South Italy) Saffron: Safranal and Its Related Compounds. J. Essent. Oil Res. 2017, 29, 221-227. [CrossRef]

26. Urbani, E.; Blasi, F.; Chiesi, C.; Maurizi, A.; Cossignani, L. Characterization of Volatile Fraction of Saffron from Central Italy (Cascia, Umbria). Null 2015, 18, 2223-2230. [CrossRef]

27. Karabagias, I.K.; Koutsoumpou, M.; Liakou, V.; Kontakos, S.; Kontominas, M.G. Characterization and Geographical Discrimination of Saffron from Greece, Spain, Iran, and Morocco Based on Volatile and Bioactivity Markers, Using Chemometrics. Eur. Food Res. Technol. 2017, 243, 1577-1591. [CrossRef]

28. D'Archivio, A.A.; Di Pietro, L.; Maggi, M.A.; Rossi, L. Optimization Using Chemometrics of HS-SPME/GC-MS Profiling of Saffron Aroma and Identification of Geographical Volatile Markers. Eur. Food Res. Technol. 2018, 244, 1605-1613. [CrossRef]

29. Variance-Optimal Designs. In Response Surfaces, Mixtures, and Ridge Analyses; John Wiley \& Sons, Ltd.: Hoboken, NJ, USA, 2007; pp. 461-481. ISBN 978-0-470-07276-9.

30. Box, G.E.P.; Wilson, K.B. On the Experimental Attainment of Optimum Conditions. J. R. Stat. Soc. Ser. B (Methodol.) 1951, 13, 1-38. [CrossRef]

31. Adams, P.R. Identification of Essential Oil Components By Gas Chromatography/Mass Spectrometry, 4th ed.; Allured Pub Corp.: Carol Stream, IL, USA, 2007; ISBN 978-1-932633-21-4.

32. Kanakis, C.D.; Daferera, D.J.; Tarantilis, P.A.; Polissiou, M.G. Qualitative Determination of Volatile Compounds and Quantitative Evaluation of Safranal and 4-Hydroxy-2,6,6-Trimethyl-1-Cyclohexene-1-Carboxaldehyde (HTCC) in Greek Saffron. J. Agric. Food Chem. 2004, 52, 4515-4521. [CrossRef]

33. Cid-Pérez, T.S.; Nevárez-Moorillón, G.V.; Ochoa-Velasco, C.E.; Navarro-Cruz, A.R.; Hernández-Carranza, P.; Avila-Sosa, R. The Relation between Drying Conditions and the Development of Volatile Compounds in Saffron (Crocus sativus). Molecules 2021, 26, 6954. [CrossRef]

34. Anastasaki, E.; Kanakis, C.; Pappas, C.; Maggi, L.; del Campo, C.P.; Carmona, M.; Alonso, G.L.; Polissiou, M.G. Geographical Differentiation of Saffron by GC-MS/FID and Chemometrics. Eur. Food Res. Technol. 2009, 229, 899-905. [CrossRef]

35. Tahri, K.; Bougrini, M.; Saidi, T.; Tiebe, C.; El Alami-El Hassani, N.; El Bari, N.; Hübert, T.; Bouchikhi, B. Determination of Safranal Concentration in Saffron Samples by Means of VE-Tongue, SPME-GC-MS, UV-Vis Spectrophotometry and Multivariate Analysis. In Proceedings of the 2015 IEEE SENSORS, Busan, Korea, 1-4 November 2015; pp. 1-4.

36. D'Auria, M.; Mauriello, G.; Racioppi, R.; Rana, G.L. Use of SPME-GC-MS in the Study of Time Evolution of the Constituents of Saffron Aroma: Modifications of the Composition During Storage. J. Chromatogr. Sci. 2006, 44, 18-21. [CrossRef] 